\title{
Habilidades sociais na infância: uma experiência nos Anos Iniciais
}

Fernanda Vebber

Alessandra Bencke Jardim**

Resumo: O Projeto Habilidades sociais na infäncia: uma experiência nos Anos Iniciais propõe a sensibilização às habilidades sociais em sala de aula como uma possível estratégia para desenvolver habilidades e competências sociais e melhorar as relações interpessoais considerando a função social da escola e a perspectiva de promoção da qualidade de vida e saúde na infância e adolescência. Esta proposta orientou-se pelas pesquisas de Zilda Del Prette e Almir Del Prette e foi desenvolvida no decorrer do ano letivo com os alunos do primeiro ano do Ensino Fundamental, tendo como foco as habilidades de autocontrole/ expressividade emocional e de fazer amizades. De modo geral, observou-se redução na freqüência de conflitos interpessoais e respeito ao cumprimento de combinações da turma que envolviam a consideração ao outro.

Palavras-chave: Habilidades sociais; Infância; Relações interpessoais.

Abstract: The Project Social skills in childhood: an experience in Elementary School proposes to raising awareness of social skills in the classroom as a possible strategy for developing abilities and social skills and improve interpersonal relations considering the

Psicóloga Escolar nos Anos Iniciais do Ensino Fundamental do Colégio de Aplicação (UFRGS), Especialista em Psicopedagogia (PUCRS) e Mestre em Educação (UFRGS).

** Pedagoga (UFRGS) e Professora Substituta nos Anos Iniciais do Ensino Fundamental do Colégio de Aplicação (UFRGS). 
social role of school and the prospect of promoting the quality of life and health in childhood and adolescence. This proposal was guided by Zilda Del Prette and Almir Del Prette researches and was developed during the school year with students in the first year of elementary school, focusing on the skills of self-control/ emotional expressiveness and making friends. Overall, there was a reduction in the frequency of interpersonal conflicts and an improvement of class combinations' performance regarding others.

Keywords: Social skills; Childhood; Interpersonal relationships.

O Projeto Habilidades sociais na infância: uma experiência nos Anos Iniciais foi desenvolvido ao longo do ano de $2010 \mathrm{com}$ a turma do primeiro ano do Ensino Fundamental do Colégio de Aplicação, com crianças de seis a sete anos. Os encontros aconteceram quinzenalmente, em dois períodos de aula.

Considerando a visão da escola quanto a sua função cultural de preparação para a vida e a ocorrência de conflitos entre os alunos no ambiente escolar, buscamos desenvolver um projeto de ensino já no primeiro ano de escolarização das crianças a fim de desenvolver habilidades e competências sociais e melhorar as relações interpessoais numa perspectiva de promoção da qualidade de vida e prevenção de problemas na infância e adolescência. Este projeto orientou-se pelas investigaçôes de Del Prette e Del Prette $(2003 ; 2005)$ sobre a viabilidade e a necessidade de incluir as habilidades sociais como objetivos de uma educação comprometida com a formação para a cidadania e para a vida social em geral. Seguindo o viés preventivo, as dificuldades interpessoais na infância são mais prováveis de serem superadas se atendidas precocemente (LOEBER, 1991), o que reforça o investimento na qualidade dos relacionamentos interpessoais da criança através de estratégias educativas como esta, que primam pela saúde psicológica e bem-estar das crianças. Para o trabalho com o primeiro ano do Ensino Fundamental foram priorizadas duas das sete classes de habilidades sociais apresentadas por Del Prette e Del Prette (2005): autocontrole/expressividade emocional e fazer amizades. 
Tendo em vista a dinâmica dos relacionamentos interpessoais, $\mathrm{o}$ repertório lúdico das atividades utilizadas e a proposta pedagógica da escola, percebemos que as demais classes de habilidades sociais também foram contempladas no desenvolvimento deste projeto ${ }^{1}$.

No primeiro semestre, trabalhamos o autocontrole e a expressividade emocional, que incluem as habilidades de

[...] reconhecer e nomear as emoções próprias e dos outros, controlar a ansiedade, falar sobre emoçôes e sentimentos, acalmar-se, lidar com os próprios sentimentos, controlar o humor, tolerar frustrações, mostrar espírito esportivo, expressar as emoções positivas e negativas (DEL PRETTE; DEL PRETTE, 2005, p. 46).

Através de atividades diversificadas e de forma lúdica, os alunos estiveram envolvidos com contação de história, brincadeiras, interpretação teatral, jogos e desenhos.

As práticas de caráter lúdico, interativo, que permitem que o professor utilize procedimentos e técnicas para a promoção de desempenho social dos alunos, são essenciais para a superação das dificuldades interpessoais dos alunos (DEL PRETTE; DEL PRETTE, 2003).

No primeiro encontro, marcado pela introdução ao projeto e apresentação dos alunos, realizamos um jogo de integração, onde cada aluno se apresentava com seu nome e fazia um gesto que o representasse e toda a turma imitava o gesto. A atividade foi divertida, os alunos riram de seus gestos, e todos participaram e conheceram melhor o jeito de cada um, inclusive os que se mostravam mais introspectivos.

No segundo encontro, apresentamos uma pequena caixa aos alunos, na qual estava escrito "caixinha de Questionamos o que seria essa caixa, e, após algumas sugestões, os alunos disseram que era uma caixinha de sentimentos. Eles demonstraram curiosidade em descobrir o que ela continha, e explicamos-lhes que com a história da Caixa de Pandora

$1 \quad$ As classes de habilidades sociais apresentadas por Del Prette e Del Prette (2005) são: autocontrole e expressividade emocional, civilidade, empatia, assertividade, fazer amizades, solução de problemas interpessoais e habilidades sociais acadêmicas. 
compreenderíamos seu conteúdo. Enquanto contávamos a história, em diferentes momentos, os alunos foram convidados a refletir sobre como estaria se sentindo Pandora e como agiriam se estivessem em seu lugar. Assim, introduzimos o tema sobre os sentimentos e, ao final da história, os alunos puderam comentar a história e descobrir que dentro da caixa havia sentimentos escritos em papéis coloridos. Cada aluno retirou um papel e combinamos que não poderia mostrar aos demais colegas. Todos já sabiam que eram sentimentos e alguns necessitaram de auxílio para ler. Os alunos foram convidados a demonstrar, com a expressão do rosto, gestos, a posição do corpo (sem falar), o sentimento que retiraram da caixa, para o restante do grupo adivinhar. Finalizamos este encontro refletindo sobre a importância de se conhecer os próprios sentimentos e de aprender a lidar com eles. Surgiram falas como:

- É bom ter sentimentos, é bom ser feliz.

- Com os sentimentos sabemos como as pessoas estão!

No terceiro encontro, com a história sobre o Parque das Emoções, foram exploradas diferentes emoçôes através de situações vivenciadas pelos personagens. A partir dessa história, começamos a trabalhar os diferentes sentimentos que cada um poderia ter, refletindo como cada pessoa pode lidar com o que sente e como lidar com as emoções dos outros.

Durante o projeto, em vários momentos em sala de aula, surgiram conflitos, e algumas vezes os alunos lembraram do que estava sendo trabalhado e diziam:

- Hoje en fiquei muito bravo com o colega, queria bater nele, porque ele me irritou muito!

A partir desses dizeres, pudemos reconhecer a emoção sentida, conversar sobre como agir nessa situação e como controlar nossos sentimentos. Também refletíamos sobre como o colega poderia agir conosco para termos um bom convívio, onde cada um respeitasse o sentimento do outro.

No quarto encontro, cada aluno comentou sobre como estava se sentindo. Predominaram os sentimentos mais conhecidos, 
como alegria, raiva e tristeza. Então, conversamos sobre como as cores podem representar aquilo que sentimos, em exemplos como: "Carlos ficou verde de inveja...", "Marcela estava vermelha de raiva (ou vergonha)...”, "O garoto, desapontado, não conseguiu evitar o sorriso amarelo...”.

No último encontro do primeiro semestre, confeccionamos um termômetro do humor, no qual cada aluno pode diariamente identificar seus sentimentos: confiante; feliz; esperto; irritado; triste. Brincamos também com um jogo de memória e outro de reconhecimento dos sentimentos em diferentes contextos. Os alunos imaginavam o que poderiam sentir e conversavam com os colegas sobre maneiras de lidar com a situação.

Percebemos que, depois desse trabalho, os alunos identificavam seus sentimentos com mais facilidade e, algumas vezes, os dos colegas, demonstrando assim conhecerem melhor a si mesmos e procurando auxiliar os pares nesse processo de autoconhecimento. Também observamos que os alunos procuravam resolver mais frequentemente seus conflitos através do diálogo.

No segundo semestre, a temática do projeto foi Amizades. Fazer amizades inclui, entre outras habilidades: "[...] fazer perguntas pessoais; responder perguntas; aproveitar as informações livres oferecidas pelo interlocutor; sugerir atividade; cumprimentar e apresentar-se; elogiar e aceitar elogios; oferecer ajuda, cooperar; iniciar e manter conversação” (DEL PRETTE; DEL PRETTE, 2005, p. 47).

A primeira atividade foi a contação da história Rápido como um gafanhoto, que traz características dos animais que podem ser associadas com tudo aquilo que podemos ser: corajosos, educados, rápidos, lentos, maus, bons, meigos,... Conversamos sobre como cada um se percebia, com qual característica de animal se identificava, e, em seguida, cada um fez um desenho partindo da proposta: "Como eu sou?" (Figuras 1 a 4). 
Figura l - Eu sou um coelho. Eu sou o melhor amigo das crianças e eu sou bonzinho. Essa é minha vida

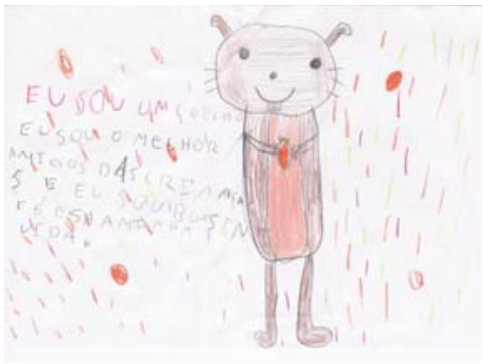

Figura 3 - Sou o gato preguiçoso

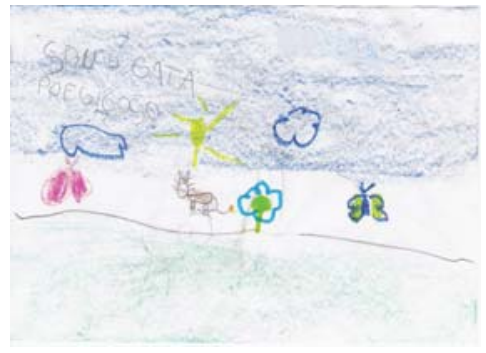

Figura 2 - Sou grande como uma girafa

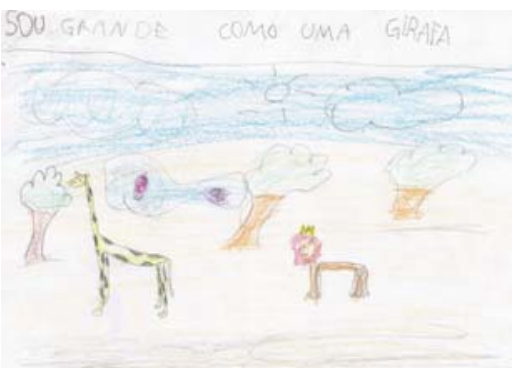

Figura 4 - Sou um pouco de cada coisa do universo

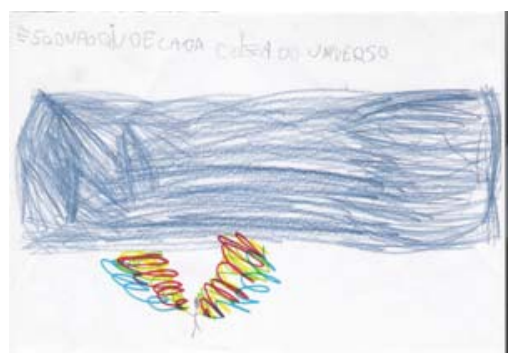

Foi interessante perceber que os alunos conseguiam se identificar com as características associadas aos animais, explorando o seu autoconhecimento. Com suas produçôes construímos um mural na sala de aula e todos ficaram durante a semana olhando e comentando o que o colega tinha desenhado. Alguns até diziam que o colega se parecia mesmo com o que tinha feito.

No encontro seguinte, a atividade proposta foi uma entrevista em duplas, as quais foram estipuladas considerando alunos que não costumavam brincar ou trabalhar juntos. Esta atividade criou a possibilidade de os colegas se conhecerem melhor e ampliarem seu círculo de amizades. As duplas se espalharam pelo chão da sala e realizaram as entrevistas. Os alunos perceberam que tinham gostos iguais aos dos colegas e reconheceram algumas diferenças, considerando tais descobertas interessantes. 
Identificaram também como o colega gostava de ser tratado, o que gostava de ouvir dos outros e se havia algo de que não gostavam. Em seguida, no grande grupo, compartilharam suas descobertas sobre os colegas. Em alguns momentos, na sala de aula, depois dessa atividade, foi possível perceber que eles chamavam a atenção de alguns colegas, dizendo:

- Marcos ${ }^{2}$ a Luana não gosta de ser chamada de chata! Demonstraram, assim, tentativas de auxiliar uns aos outros nas amizades.

No terceiro encontro, realizamos uma atividade integrada com a professora de teatro, que explorou, através de exercícios teatrais, a história Rápido como um gafanhoto.

No quarto encontro, exploramos as imagens de um livro que trata sobre situações em que as crianças pensam de formas diferentes. Alguns alunos expuseram situações que vivenciavam com os colegas e como procuravam solucioná-las, mesmo quando pensavam de formas diferentes. Fizemos um correio de elogios, onde a partir de um sorteio de amigo secreto os alunos escreveram cartas com elogios para o colega sorteado.

No último encontro do segundo semestre, contamos a história Pedro e Tina, através da qual foi possível explorar diferenças individuais e o que podemos aprender com uma amizade. Após a contação da história, discutimos sobre as características de cada personagem e como era a amizade deles. Conversamos sobre ter amigos e nossas diferenças, como respeitar cada um e aprender com o jeito do outro. Para finalizar a atividade, os alunos desenharam algo que tinham aprendido com os colegas durante o ano (Figuras 5 a 7). Surgiram diversos dizeres e, conforme iam terminando o trabalho, alguns espontaneamente foram escrevendo cartas para os colegas, surgindo assim um novo correio de elogios. A atividade foi gratificante, pois percebemos os avanços dos alunos no que diz respeito à convivência e às relações de amizade.

2 Os nomes utilizados são representativos. 
Figura 5 - Aprendi a dividir.

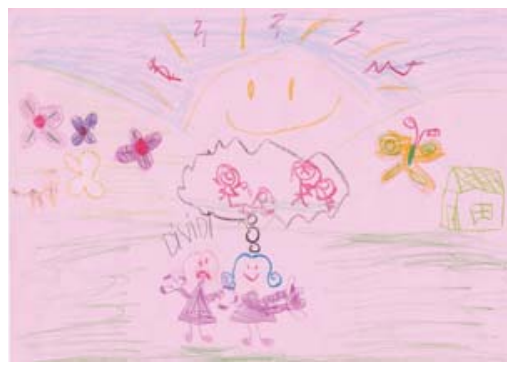

Figura 6 - A criança pode fazer errado, mas a outra criança pode gostar dela.

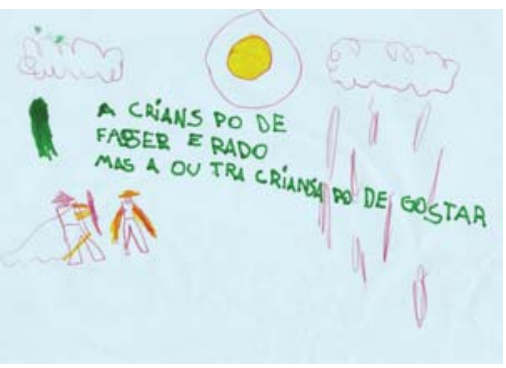

Figura 7 - Eu aprendi no livro que quando uma amizade se revela um ensina o outro amigo.

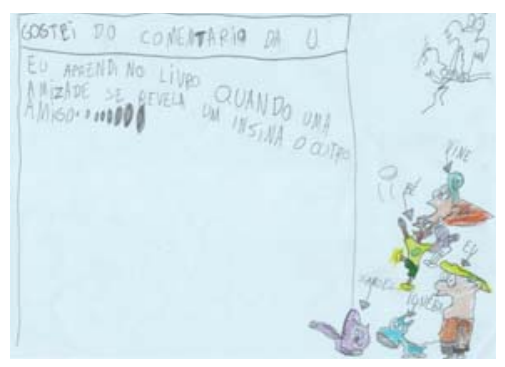

Concluindo esse relato, podemos dizer que nossa experiência em sala de aula foi gratificante e que é importante trabalhar essas habilidades sociais desde o início da escolarização. Através desse projeto, os alunos puderam crescer ao longo desse ano aprendendo a se conhecer mais: na identificação de seus sentimentos e em sua expressão, e no manejo das emoções, suas e dos outros. Conhecendo-se melhor, os alunos descentraram-se de si mesmo e passaram a considerar mais os outros, identificando o que sentiam, procurando tratar melhor o colega, criando e cultivando amizades. Percebemos o crescimento de cada aluno; aqueles mais introspectivos passaram a participar mais em sala de aula, e o diálogo foi mais utilizado para resolver conflitos e compreender os colegas. 
A parceria entre psicóloga e pedagoga proporcionou atividades aplicadas com olhar diferenciado e complementar. A integração da visão das duas áreas pode auxiliar os alunos em suas diferentes necessidades, ampliando o repertório das potencialidades interpessoais dentro de suas vivências escolares, que dessa forma contribuíram para o seu processo de desenvolvimento e de aprendizagem.

\section{Referências}

DEL PRETTE, Zilda; DEL PRETTE, Almir. Habilidades sociais e educação: Pesquisa e atuação em psicologia escolar/educacional. In: DEL PRETTE, Zilda (Org.). Psicologia escolar e educacional, saúde e qualidade de vida. 2. ed. Campinas: Alínea, 2003. p. 113-141.

DEL PRETTE, Zilda; DEL PRETTE, Almir. Psicologia das habilidades sociais na infância: teoria e prática. 2. ed. Petrópolis: Vozes, 2005.

KING, Stephen Michael. Pedro e Tina: uma amizade muito especial. São Paulo: BRINQUE-BOOK, 1999.

LOEBER, Rolf. Antisocial behavior: More enduring than changeable? Journal of the American Academy of Child \&Adolescent Psychiatry, n. 30, p. 393-397, 1991.

RASTOIN-FAUGERON, Françoise. As emoções: por que sentimos medo? São Paulo: Escala Educacional, 2008.

ROCHA, Ruth; LORCH, Dora. As dúvidas que eu tenho. São Paulo: Ática, 2006.

STALLARD, Paul. Bons pensamentos - Bons sentimentos. Porto Alegre: Artmed, 2004.

WOOD, Audrey. Rápido como um gafanhoto. 2. ed. São Paulo: BRINQUE-BOOK, 2007. 